\title{
A CÔR EM RELAÇÃO AO TEOR DE UMIDADE DE ALGUMAS SERIES DE SOLOS (1)
}

Arnaldo Guido de Souza Coel.ho e Raul Aud, engenheirosi-agrônomos, Servifo de Fotointerpretação, Instituto Agronômico.

\section{RESUMO}

A identificação e a classificação dos solos em séries são baseadas em várias características, das quais uma é a côr. Esta é condicionada por um grupo de fatôres, destacando-se o relacionado ao teor de umidade do solo.

Para observar e estabelecer os limites de variaçăo da côr do solo com a umidade, os autores, empregando o sistema Munsell, trabalharam com amostras naturais e preparadas das principais séries monotípicas que ocorrem na Estaçẩo Experimental do Instituto Agronômico, em Campinas:

As sérics monotípicas de drenagem imperfeita é que mostraram sofrer maior influência da umidade na sua cồr. A côr das amostras preparadas (TFSA) não se mostron representativa das séries.

A variação da limidade atua de forma mais rápida e significativa sôbre o «valor», exceto para as terras-roxas, onde o ccroma» se mostra mais sensivel. A componente da côr menos influenciada pela variação da umidade é o kcolorido».

$\mathrm{Na}$ determinação da côr das séries analisadas, os autores também verificaram a influência de outros fatôres, como: luz ambiente, hora da determinaçăo, estado da tabela padräo e exposição da amostra ao ar.

\section{1 - INTRODUÇÃO}

Na classificação dos solos em séries levam-se em consideração : morfologia, textura, estrutura, côr, posição topográfica e matęrial original.

Aparentemente, o fator cór é dos mais fáceis e de pronto reconhecimento. Contudo, varia extremamente de um solo para outro e, dentro de um mesmo perfil, nos horizontes e nas camadas de transição.

A côr é função variável de um grupo de fatôres, quais sejam,

(1) Trabatho apresentado no IX Congresso Brasileiro de Ciéncia do Solo, realizado em Fortaleza, Ceará, de 15 a 23 de julho de 1963 . Recebido para publicaçắo a 6 de abril ed ţ̧64. 
material original, meteorização, matéria orgânica, clima, topografia e homem. Estes fatôres condicionam o fenômeno, mas sua identificação é algo de caráter pessoal, não se podendo afirmar que uma mesma côr seja interpretada de forma igual por diferentes pessoas. Uma côr, grísea para um observador, poderá ser cinzenta para outro $\left({ }^{2}\right)$. Essas variações são, em grande parte, evitadas com o emprêgo de tabelas ou cartas de côres padrões, como a «Munsell Soil Color Charts» (2), usada no presente trabalho.

A côr depende ainda do teor de umidade e do preparo da amostra. No primeiro caso, varia com o estado do tempo e, no segundo, com o preparo do solo para análise.

Embora o problema da côr em relação à umidade seja importante na classificação e no levantamento de solos, a bibliografia consultada não fornece dados sôbre os limites de variação de uma em função de oitra:

Theron e Van Niekerk, segundo Mohr e Van Baren (1), afirmam qự ưm solo cuja matéria mineral está numa relação molecular sílica-óxido de ferro maior que 2.4. é muito mais fàcilmente colorido pelo hưmus que outro com baixa relação. Por outro lado, segundo Robinson (4), a variação de côr de amostras sêcas e reumedecidas em laboratório não é perfeitamente reversível.

Sendo muitas as causas da variação da côr do solo, devem-se admitir, para cada série, limites de oscilação para sua côr, a fím de não se cair em outra série $(5,6,7)$.

Com o presente trabalho. os autores procuram verificar a influência do teor de umidade sôbre a côr do solo natural, sua correlação com as determinações de umidades feitas em amostras de solos preparados em laboratórios e a comparação com os limites estabelecidos para as séries. Se determinado teor de umidade fôsse suficiente para fazer a côr do solo fugir de seus limites de descrição, as determinações só deveriam ser feitas num estado de umidade fora daquele teor.

Da mesma forma, se o trabalho mecànico sofrido pelas amostras em laboratório (destorroamento, moagem, tamisação etc.) fôsse suficiente para conduzir a côr do solo de uma dada série para fora de seus limites de variação, seria necessário preconizar outras normas, para a determinação da côr do solo em laboratório.

(2) Grisea, mistura de branco e prêto; cinzenta, mistura de branco, prêto e outras. 


\section{2 - MATERIAL E METODO}

As experiências foram feitas com séries monotípicas da Estação Experimental «Theodureto de Camargo», do Instituto Agronômiço em Campinas, sendo as amostras colhidas com trado, ao lado dos perfis típicos, perfurando-se até $1 \mathrm{~m}$ de profundidade e recolhendo-se 6 amostras. Cada uma recebeu o número do perfil e uma letra minúscula de a a $\mathrm{f}$, correspondendo, a partir da superfície, às profundidades 0-10, 10-20, 20-40, 40-60, 60-80 e 80-100 cm, respectivamente. As amostras foram levadas ao laboratório, acondicionadas em vasilhame adequado, de modo a não perder água por evaporação.

As séries, de acôrdo com suas condiçōes de drenagem, foram separadas em «bem drenadas» e «imperfeitamente drenadas» $\left({ }^{3}\right)$, tomando-se como referència os limites de variação de côr estabelecidos por Verdade $\left({ }^{4}\right)$, na chave de campo para classificação de solos.

Da subordem Latossolo, foram estudadas as séries bem drenadas Chapadão (perfil 869), Taquaral (perfis 864 e 872), Barão (perfis 863 e 871) e Venda Grande (perfil 856). As séries Chapadão e Taquaral são derivadas de diabásio, com mistura de sedimentos areno-silto-argilosos do Glacial. A primeira, com pequena ou sem contribuição dos sedimentos que são notados no campo, para a segunda. As séries Barăo e Venda Grande tèm sua origem em sedimentos areno-silto-argilosos do Glacial, sendo a primeira de coloração vermelha e a segunda, amarela.

Da subordem Hidromórfica, drenagem imperfeita, estudou-se a série Monjolinho (perfil 859 ) $\left(^{5}\right)$. Seu material original é formado por sedimentos areno-silto-argilosos do Glacial, mais ou menos gleisados pela influência do lençol freático pouco profundo.

Do grande grupo Bog, foi estudada a série Haras, (perfil 873), de drenagem má. E um solo localizado em bacias de acumulação de matéria orgânica .

Do grande grupo Aluvião, estudaram-se as séries Lagoa (perfil 877), de drenagem má, e Tijuco (perfil 878), de drenagem imperfeita. O primeiro é um solo aluvial altamente argiloso, intensamente gleisado em tôdas as camadas, cujo material de origem é representado por sedi: mentos dominantemente originados do diabásio e pequena contribuj-

(2) Nome genérico pera as classes de drenagem imperfeita, a má.

(4) Năo publicado.

(s) Transição para Latossolo. 
çăo de rochas do Glacial, enquanto o segundo é um solo aluvial, formado por deposições recentes de sedimentos argilosos de diabásio e Glacial, com côres vermelhas, na superfície, e gleisado, em profundidade.

Num ensaio preliminar com terra fina sêca ao ar (TFSA) das camadas a e d dos pèrfis 857 - série Venda Grande, 858 - série Monjolinho, 864 - série Taquaral e 877 - série Lagoa, foram determinadas as côres das amostras, com os seguintes teores de umidade: saturada, isto é, a primeira fase de preparo da amostra para determinação da umidade equivalente (u.Eq.) (3); úmida até a capacidade de campo (C.c.) (3) ; umidade equivalente (3); parcialmente sêca ao ar, isto é, as amostras que se encontravam no teor de umidade equivalente, foram deixadas nas caixetas a evaporar livremente durante 5 horas; sêca ao ar (umidade higroscópica) (3), exposição ao ar durante 48 horas e sêca em estufa a $50-60^{\circ} \mathrm{C}$, isto é, as amostras com teor de umidade equivalente foram levadas à estufa a $50-60^{\circ} \mathrm{C}$ durante 4 horas.

Os autores determinaram, independentemente, as côres nas amostras naturais. As determinações no campo foram feitas sempre com boa iluminação, porém à sombra do corpo e nunca com luz direta sôbre a amostra e tabela. No laboratório, as côres foram determinadas, por um autor, em local de máxima iluminação, porém nunca com luz direta, e a segunda determinaçăo, feita pelo outro, sempre em local escolhido como têrmo médio de iluminação ambiente.

As condições de umidade para estudar as variações de côres foram as seguintes: sêca a $105-110^{\circ} \mathrm{C}$, por tempo mínimo de 24 horas; sêca a $105-110^{\circ} \mathrm{C}$ e moida em almofariz; sêca a $50-60^{\circ} \mathrm{C}$ ( 6 horas); sêca ao ar (48 horas); pouco umedecida e saturada. Nestes dois últimos casos, teve-se a preocupação de deixar as amostras com teores abaixo e acima da capacidade de campo (3). Para isto, usaram-se recipientes de alumínio com o fundo coberto por papel-filtro, sôbre o qual foram colocadas as amostras. Adicionada água às mesmas, os recipientes foram fechados e deixados em repouso durante 48 horas para homogeneização, após o que se determinaram a côr e à umidade.

As variações de côr também foram estudadas na terra fína sêca ao ar (3) e nos micromonólitos. Estes foram tratados com Vinylite, resina sintética transparente, considerada incapaz de modificar a côr do solo.

Quanto às determinaçōes com amostras moídas em almofariz, utilizaram-se apenas amostras sêcas a $105-110^{\circ} \mathrm{C}$, pelo fato de não ocorrer 
variação entre as amostras sêca ao ar, sêca a $50-60^{\circ} \mathrm{C}$ ou $105-110^{\circ} \mathrm{C}$, quando moidas.

\section{3 -- RESULTADOS OBTIDOS}

\section{1 - ENSAIO PRELIMINAR}

Do ensaio preliminar, cujos resultados estão registrados no quadro 1, deduziu-se que as corres das amostras nos estados parcialmente sêca ao ar e umidade equivalente, são idênticas em todos os perfis, nas duas camadas estudadas. A diferença observada na côr das amostras, sêca em estufa a $50-60^{\circ} \mathrm{C} / 4$ horas e a côr na umidade equivalente, foi insignificante, o mesmo ocorrendo para as amostras saturada e na capacidade de campo.

As maiores diferenças de côr foram encontradas entre as amostras de TFSA e saturada, seguidas da TFSA e capacidade de campo.

Por outro lado, solos como o do perfil 859 - série Monjolinho, mudam repentinamente a côr, passando de um colorido (hue) 5YR para 10YR, quando o teor de umidade da TFSA é levado a um mínimo acréscimo, mantendo constante, daí para diante, o colorido $10 \mathrm{YR}$, até o estado de amostra saturada e com variações de apenas uma unidade no valor (value) conservando-se constante o croma (chroma).

As alterações de côr são produzidas por pequenos aumentos no teor de umidade, principalmente quando a amostra passa de sèca para úmida e vice-versa. não havendo necessidade de se tomarem pontos fixos, como capacidade de campo, umidade equivalente ou outras, para o prosseguimento do trabalho.

\section{2 - RELAÇAO ENTRE AS CORES DAS AMOSTRAS DO ESTADO NATURAL E SUAS CORRESPONDENTES UMIDAS}

Tomando-se a amostra natural como, padrão, observou-se que tanto para os solos bem drenados como para os imperfeitamente drenados, as variações de còr das amostras úmidas (saturada e pouco umedecida) para suas correspondentes naturais, foram muito pequenas.

No quadro 2, dos resultados para os perfis 877 - série Lagoa e 859 - série Monjolinho, que apresentaram as maiores variações no grupo das imperfeitamente drenadas, pode-se observar que apenas o 


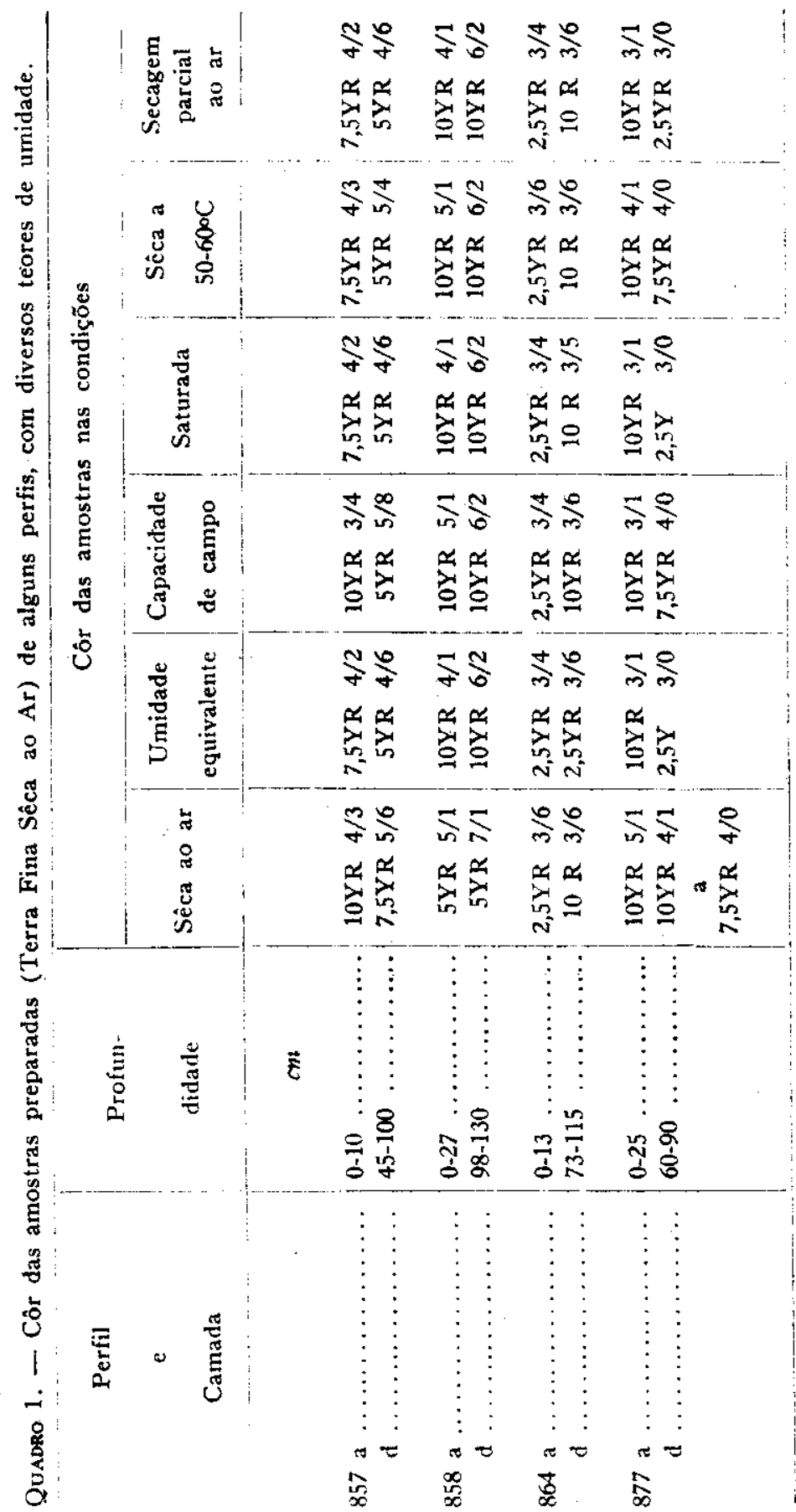


Camada e

profundidade

$(\mathrm{cm})$

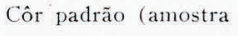

na condição de

Saturada

campo)

P. 877 - Ś́RIE LAgOA ${ }^{2}$

, $0-10 \ldots \ldots \ldots \ldots \mid 10 \mathrm{YR} \quad 3 / 1$

b $10-20 \ldots \ldots \ldots \ldots$ 10YR $2,5 / 1$

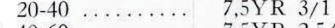

$60-80 \ldots \cdots \cdots \cdots, \quad 7,5 \mathrm{YR} 3 / 0$

$80-80$

7,5 Y R $3 / 0$
7,5 Y R $3,5 / 0$

P. 859 - Série. Monjolinho"

$0-10 \ldots$ 10YR $4,25 / 1,00$

b $10-20 \ldots \ldots \ldots$ 10YR $4,25 / 1,00$

10YR 425/100

c. $20-40$

10YR $4,25 / 1,00$

$60-80$

$10 \mathrm{YR}, 5 / 1,25$

10YR

$\begin{array}{ll}1,00 & \cdots \\ 1,25 & \cdots \\ 1,50 & \cdots\end{array}$

OYR $5,25 / 1,2$

P. 863 - Série Barão

a $0-10$

b) $10-20$

5 a 7,5 YR $3,75 / 3,75$

c $20-40$

5 a $7,5 \mathrm{YR} 4 / 4$

d $40-60$

2,5 a 5 YR $4 / 4,5$

$\begin{array}{ll}\text { e } & 60-80 \\ \text { f } & 80-100\end{array}$

5 YR $4 / 6$ 5 YR $4 / 6,5$

P. 864 - SÉrie TAQUARAL

a $0-10$

b) $10-20$

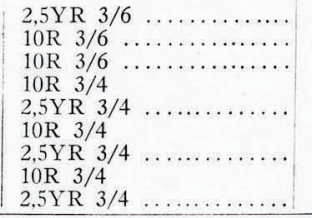

umedecida

\section{Sêca a}

$50-60 \circ \mathrm{C}$
Sêca a

$105-1100 \mathrm{C}$
Sêca a

ar

\begin{tabular}{ll|} 
& \\
$0,50 /-0,50^{4}$ \\
$1,25 /$ & 0,00 \\
$1,00 /$ & 0,00 \\
$1,50 /$ & 0,00 \\
$1,25 /$ & 0,00 \\
$0,75 /$ & 0,00
\end{tabular}

$0,50 / 0,25$

$1,25 / 0,00$

$0,50 / 0,00$

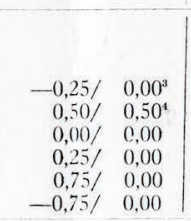

$1,50 / \quad 0,25^{\circ}$

$1,00 / 0,50^{6}$

$0.75 \% 0,00$

$0,25 / 0,00$

$0,75 / 0,00$

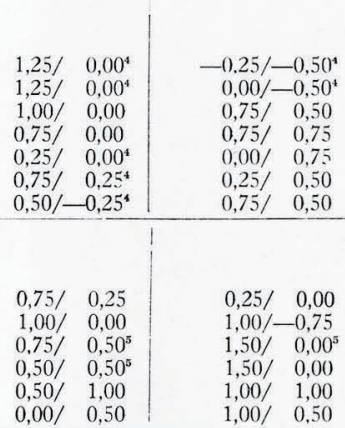

$0,00 / \quad 0,50$

$1,00 / 0,50$

$-0,25 / 0,00^{12}$

$-0,25 / \quad 0,50^{12}$

$0,00 /-0,50$

$0,00 /-1,00$

$0,00 / 0,00$

$0,00 / 2,00$

$0,00 / 2,00$

$0,00 / 2,00$

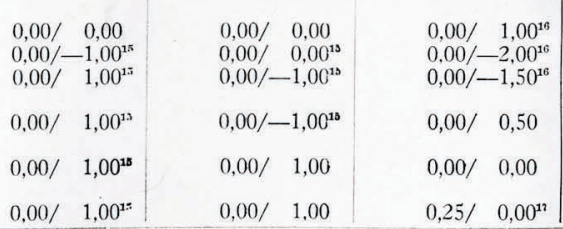

105-1100C

Moida ${ }^{1}$

$0,00 /-1,50^{13}$

$0,00 /-1,00^{15}$

$0,00 / 1,50^{16}$

$0,00 / \quad 1,50^{16}$

$0,00 / 1,00^{x}=$

$0,00 / \quad 1,00$

$0,25 / 0,00^{17}$

Terra Fina

Mịcromonó-

Sêca ao Ar

litos

\begin{tabular}{|c|c|c|}
\hline $1,50 /-0,25^{4}$ & $-{ }^{7}$ & \\
\hline $2,00 / \quad 0,00$ & $2,25 / 0,75^{\circ}$ & $\overline{1,25 /} \quad 0,50^{4}$ \\
\hline $1,00 / 0,50^{4}$ & $1,25 / 0,50^{6}$ & $0,12 / \quad 0,00$ \\
\hline $1,50 / \quad 0,00$ & $1,75 / 0,50^{6}$ & $1,25 / 0,00$ \\
\hline $2,00 / \quad 0,00$ & $1,25 / \quad 0,00$ & $0,87 / \quad 0,00$ \\
\hline $1,50 / \quad 0,00$ & $1,25 / \quad 0,00$ & $1,25 / 0,00$ \\
\hline \multirow{5}{*}{$\begin{array}{ll}1,25 / & 0,50 \\
0,75 / & 1,00 \\
1,25 / & 0,75^{\circ} \\
1,50 / & 0,50 \\
1,75 / & 0,00 \\
1,75 /-0,25 \\
1,50 / & 0,00\end{array}$} & \multirow{2}{*}{$\begin{array}{l}1,00 / \quad 0,50^{9} \\
1,75 /-0,75\end{array}$} & $0,25 / \quad 0,00$ \\
\hline & & $0,37 / \quad 0,50^{4}$ \\
\hline & $2,00 / \quad 1,00^{\circ}$ & $1,25 / 0,25^{4}$ \\
\hline & $\overline{1,75 / \quad 0,50^{\circ}}$ & $\overline{0,75 / \quad 0,75^{4}}$ \\
\hline & $1,75 / \quad 0,50$ & $0,75 / \quad 0,75$ \\
\hline $1,75 / 1,00^{4}$ & $0.50 / \quad 0,25$ & $0,25 /-1,38$ \\
\hline $1,50 / \quad 2,00^{13}$ & $1,00 / 0,00^{5}$ & $0,00 /-0,25^{5}$ \\
\hline $1,50 / \quad 1,50^{13}$ & $1,00 / \quad 0,00^{\mathrm{s}}$ & $0,25 / \quad 0,50^{5}$ \\
\hline $2,00 / 1,50$ & $\overline{1,00 / \quad 0,00}$ & $\overline{0,00 / \quad 0,00}$ \\
\hline $1,75 / \quad 0,50^{13}$ & $1,00 / 1,00$ & $0,25 /-1,00$ \\
\hline
\end{tabular}

\begin{tabular}{ll|ll}
$1,00 /$ & $1,00^{5}$ & $0,00 /$ & 0,00 \\
$1,00 /$ & $1,00^{5}$ & N $^{18}$ \\
$1,00 /$ & $1,00^{5}$ & $0,00 /$ & $0,00^{15}$ \\
$1,00 /$ & $3,00^{12}$ & $0,50 / 2,00^{12}$ \\
$1,00 / 2,50^{12}$ & & \\
$2,50 /$ & $2,00^{15}$ & $0,50 / 2,00^{5}$
\end{tabular}

$0,13 /-2,00_{18}$

$0,00 /-2,00^{15}$

$0,00 /-2,00^{15}$

$2,50 / 2,00^{15}$

$0,50 / 2,00^{5}$

$0,00 / 2,00^{16}$

ObServações: ${ }^{1}$ Sêca a $105-110{ }^{\circ} \mathrm{C}$, moída nos dedos, exceto P. 877; ${ }^{2}$ Sêca a $105-110^{\circ} \mathrm{C}$, moída no gral de porcelana; ${ }^{3} \mathrm{Matiz} 5$ a $10 \mathrm{YR}$; ${ }^{4} \mathrm{Matiz} 7,5$ a $10 \mathrm{YR}$; ${ }^{5} \mathrm{Matiz} 5 \mathrm{YR}$;

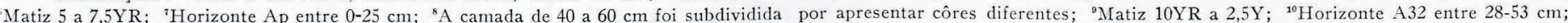

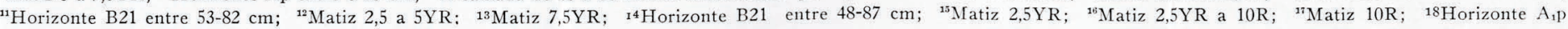
entre $0-13 \mathrm{~cm} ;{ }^{19}$ Horizonte $\mathrm{B} 21$ entre $38-73 \mathrm{~cm}$. 
colorido variou um pouco, sendo o valor e o croma, a não ser em uma das determinações, nunca atingiram uma unidade. Já no caso dos solos bem drenados, essa variação foi um pouco maior, indo de $1 / 4$ a uma unidade, tanto para o valor como para o croma, como se vê pelos resultados dos perfis 863 - série Barão e 864 série Taquaral.

Quadro 3. - Porcentagem de umidade das amostras de solos naturais.

\begin{tabular}{|c|c|c|c|c|c|c|}
\hline \multirow{2}{*}{\multicolumn{2}{|c|}{$\begin{array}{c}\text { Perfil } \\
\text { e } \\
\text { Camada }\end{array}$}} & \multirow[b]{2}{*}{ Profundidade } & \multicolumn{4}{|c|}{ A mostras } \\
\hline & & & $\begin{array}{l}\text { Condiçăo } \\
\text { natural } \\
\text { de } \\
\text { campo }\end{array}$ & 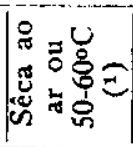 & $\begin{array}{l}\text { Pouco } \\
\text { umede- } \\
\text { cida }\end{array}$ & $\begin{array}{l}\text { Satu- } \\
\text { rada }\end{array}$ \\
\hline $\begin{array}{r}859 \mathrm{a} \\
\mathrm{b} \\
\mathrm{c} \\
\mathrm{d} \\
\mathrm{e} \\
\mathrm{f} \\
\mathrm{g}\end{array}$ & 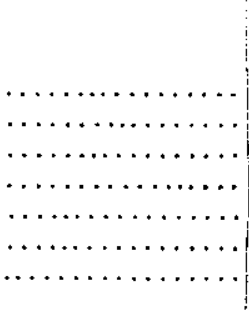 & 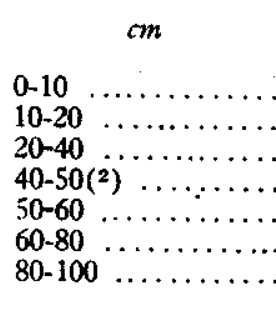 & $\begin{array}{r}8,28 \\
8,34 \\
9,11 \\
11,91 \\
13,96 \\
14,61 \\
15,60\end{array}$ & $\begin{array}{r}0,92 \\
1,20 \\
1,20 \\
- \\
1, \overline{44} \\
1,40\end{array}$ & $\begin{array}{l}15,67 \\
15,60 \\
15,14 \\
15,67 \\
18,90 \\
18,76 \\
19,97\end{array}$ & $\begin{array}{l}20,01 \\
20,03 \\
19,48 \\
20,01 \\
22,39 \\
20,08 \\
23,68\end{array}$ \\
\hline $\begin{array}{r}863 a \\
b \\
c \\
d \\
e \\
f\end{array}$ & $\begin{array}{l}\cdots \\
\cdots \\
\cdots \\
\cdots\end{array}$ & 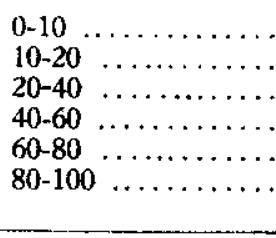 & $\begin{array}{l}12,35 \\
13,63 \\
14,81 \\
15,94 \\
14,98 \\
13,63\end{array}$ & $\begin{array}{l}1,18 \\
1, \overline{20} \\
1,20 \\
1,28 \\
1,40\end{array}$ & $\begin{array}{l}18,06 \\
18,27 \\
19,04 \\
20,77 \\
18,41 \\
17,64\end{array}$ & $\begin{array}{l}25,47 \\
24,22 \\
23,91 \\
25,94 \\
24,84 \\
22,17\end{array}$ \\
\hline $\begin{array}{r}864 a \\
b \\
c \\
d \\
\mathrm{e} \\
\mathrm{f}\end{array}$ & $\ldots \ldots \ldots$ & 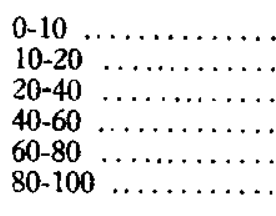 & $\begin{array}{l}11,11 \\
13,64 \\
19,05 \\
16,30 \\
11,11 \\
16,30\end{array}$ & $\begin{array}{l}1,30 \\
1, \overline{44} \\
1,28 \\
1, \overline{24}\end{array}$ & $\begin{array}{l}27,79 \\
26,42 \\
27,79 \\
28,20 \\
27,79 \\
26,58\end{array}$ & $\begin{array}{l}31,14 \\
29,44 \\
30,97 \\
31,40 \\
28,28 \\
26,82\end{array}$ \\
\hline $\begin{array}{r}877 \mathrm{a} \\
\mathrm{b} \\
\mathrm{c} \\
\mathrm{d} \\
\mathrm{e} \\
\mathrm{f} \\
\end{array}$ & $\ldots$ & $\begin{array}{l}0-10 \ldots \ldots \ldots \\
10-20 \ldots \ldots \ldots \\
20-40 \ldots \ldots \ldots \\
40-60 \ldots \ldots \ldots \ldots \\
60-80 \ldots \ldots \ldots \ldots \\
80-100 \ldots \ldots \ldots \ldots\end{array}$ & $\begin{array}{l}20,70 \\
31,40 \\
40,84 \\
37,08 \\
36,33 \\
35,40\end{array}$ & $\begin{array}{l}2 \overline{64} \\
3,72 \\
3,40 \\
3,88 \\
3,30\end{array}$ & $\begin{array}{l}23,99 \\
31,40 \\
42,09 \\
41,54 \\
36,33 \\
34,22\end{array}$ & $\begin{array}{l}30,71 \\
34,68 \\
44,92 \\
45,45 \\
41,34 \\
37,36\end{array}$ \\
\hline
\end{tabular}

(1) Observou-se haver identidade no teor para o solo natural sêco a $50-600 \mathrm{C}$

e Terra Fina Sêca ao Ar à mesma condiçăo.

(2) A camada de 40 a $60 \mathrm{~cm}$ foi subdividida por apresentar côres diferentes. 
As amostras das terras-roxas tiveram o valor inalterado, apresentando, porém, alguma variação no colorido e variações de até duas unidades no croma.

$O$ fato de as amostras úmidas das séries bem drenadas apresentarem maior variação de côr que as imperfeitamente drenadas, pode ser explicado pela proximidade das porcentagens de umidade das amostras dessas últimas, conforme o quadro 3, perfil 877 .

As diferenças de côr entre as amostras saturadas e pouco umedecidas, como pode ser observado pela análise dos resultados no quadro 2, são insignificantes, provando, assim, que, atingindo o estado úmido, a côr não mais varia de forma significativa .

A análise das amostras sêcas sem preparo (sêca ao ar, sêca a $50-60^{\circ} \mathrm{C}$ e sèca a $105-110^{\circ} \mathrm{C}$ ) em relação às suas correspondentes naturais, evidencia, tanto para os solos bem drenados como para os imperfeitamente drenados, grandes diferenças, sòmente superadas pelas amostras que sofreram outros preparos (moída e terra fina sêca ao ar).

As amostras sêcas mostram, em relação ao solo natural, grandes variações de côr em suas três componentes, colorido, valor e croma. Nestas amostras, observou-se que nos solos imperfeitamente drenados a componente mais variável é o valor, oscilando até duas unidades, isto para o perfil 877 , o de maior variação neste grupo.

Por outro lado, as amostras das séries bem drenadas apresentaram um comportamento mais equilibrado, ou seja, com o valor e croma oscilando igualmente, exceto nas terras-roxas, onde a influência da umidade se fêz sentir mais intensamente no croma que no valor.

Sendo assim, as determinações de côr dos solos bem drenados, como nas séries estudadas, podem ser feitas na amostra natural sêca em laboratório, desde que as variações experimentadas não ultrapassem aquelas devidas à umidade natural do solo.

Para os solos imperfeitamente drenados, as diferenças em relação às amostras naturais são bem maiores, indo até duas unidades no valor e cinco no colorido, o que não aconselha o emprêgo de amostras sêcas para as determinações de côres, para êstes solos. 


\section{3 - RELAÇÃO ENTRE AS CORES DAS AMOSTRAS NO ESTADO NAIURAL E SUAS CORRESPONDENTES PREPARADAS}

As amostras, moidas após secagem a $105-110^{\circ} \mathrm{C}$, TFSA e micromo. nólitos foram, com exceção das últimas, as que apresentaram maiores variações. Nas duas primeiras, as variações foram sempre grandes, quer para as séries bem ou imperfeitamente drenadas e nas três componentes da côr, indo para o colorido até cinco unidades, e para o valor e croma, em tôrno de 2,5 unidades, como aconteceu no perfil 856 .

Quanto aos micromonólitos, observaram-se variações significativas para as séries imperfeitamente drenadas, enquanto nas séries bem drenadas, as diferenças foram sempre menores que as variações normais Ja còr, em decorrência do teor de umidade das amostras. Infere-se ser viável a determinação de còr com micromonólitos, quando se tratar de solos de boa drenagem, não sendo aconselhável para solos de drenagem imperfeita.

\section{4 - CONCLUSOES}

Pela análise dos resultados obtidos com as séries estudadas, verificou-se, de forma geral, que a variação da côr é prontamente observada na passagem de solo sêco para úmido e vice-versa, sendo insignificantes as variações entre os vários teores de umidade.

Quanto às amostras moídas após secagem a $105-110^{\circ} \mathrm{C}$, TFSA e micromonólitos, notaram-se grandes variações nas duas primeiras. Os micromonólitos só apresentaram grandes variações (em relação à amostra natural) nos casos de séries de drenagem imperfeita.

Assim, podem-se tirar as seguintes conclusões :

a) De forma geral, a elevação progressiva no teor de umidade da amostra determina uma diminuição gradativa no valor e no croma, isto é, a amostra torna-se mais escura, tendendo para o neutro, e vice-versa.

b) A umidade atua de forma mais pronta e intensa no valor que no croma, exceto nas terras-roxas, onde ocorre o inverso, chegando, às vêzes, a haver mudança no colorido.

c) A componente da côr que menor variação sofre com a umidade 
é o colorido, que, em si, sofre menos variação nos solos amarelos e vermelhos (de 5YR a 10YR).

d) Nas séries bem drenadas, entre os limites aproximados de $12 \mathrm{e}$ $40 \%$ de umidade, a côr não sofre grandes variações, podendo a determinação no campo, para tais séries, ser feita sem restrições dentro dêsses limites.

e) A série Monjolinho sugere que para os solos de drenagem imperfeita, a oscilação mínima de 4 unidades deve ser considerada para o valor.

f) Para as séries estudadas, a côr da TFSA não foi representativa.

g). Os micromonólitos e a terra sêca ao ar, de solos de boa drenagem, podem ser empregados para determinação da côr.

h) Para a determinação da côr da amostra de um solo, o teor mais adequado de umidade é aquêle entre as porcentagens determinadas para a amostra em condições de campo e saturada.

i) Os estudos efetuados indicam que, nos levantamentos de solos, o fator côr deve ser considerado mais elàsticamente nas componentes valor, croma e colorido, isto é, no mínimo 2,5 unidades para as duas primeiras e 5 unidades para a última, na dependência das condições de drenagem do solo.

\section{5 - OBSERVAÇOESS COMPLEMENTARES}

Com o desenvolvimento dos trabalhos os autores verificaram que, além do teor de umidade, outros fatôres influem na côr do solo, quais sejam: 1) coleta da amostra ; 2) exposição da amostra; 3) tabela padrão; 4) luz ambiente e 5) hora da determinação.

No que se refere à coleta da amostra, observou-se que, sempre que possível, deve-se determinar a côr com um pequeno torrão, a fim de conservar a estrutura natural do solo.

Algumas amostras, notadamente dos solos com mosqueamento, quando expostas ao ar, em um tempo relativamente curto mudam a côr, devido à rápida oxidação de seus componentes, o que indica que, para 
elas, devem ser feitas duas determinações de côr, antes e após a oxidação.

Comparando os padrões de duas tabelas com, aproximadamente, o mesmo tempo de uso, observou-se ocorrerem diferenças visíveis entre elas. Daí sugerir-se que seja usada sempre a mesma tabela nas determinações, para posteriores comparações.

Procurou-se verificar a influência da luz ambiente na determinação da côr da amostra, sob condições normais de laboratório.

A côr determinada para certa amostra foi $5 Y R$ 4/4-4/6, ou seja, bruno-avermelhada a vermelho-amarelada, após exame na melhor condição de luz natural reinante no laboratório, passando, porém, a mesma amostra a ser definida como $2,5 \mathrm{YR} 4 / 6-4 / 8$, isto é, vermelha a vermelhoescura, depois de examinada no mesmo lugar, mas observada à sombra oferecida pelo corpo do observador (Observações feitas em amostras do P. 871).

Observou-se que as sombras determinam escurecimento nas amostras; daí, a importância da padronização da forma pela qual as amostras são examinadas. Necessário se torna evitar observações sob condições diferentes, principalmente quando se visa comparar resultados.

Para as determinações de campo, sugere-se que nunca sejam feitas com luz que incida diretamente sôbre as amostras, mas sim à sombra. em local de iluminação uniforme, ou à sombra do corpo, após esperar-se a adaptação visual.

Julga-se útil especificar sempre as condições de iluminação para dada determinação de côr, pois, dessa forma, poder-se-ão explicar as diferenças encontradas em várias determinações.

Tal como a iluminação do local, a hora do dia deve ser considerada nas determinações de corres. Assim, se forem feitas duas determinações, de manhã e à tardinha, por exemplo. será notada sempre diferença nessas observações, embora nem sempre significativas, pois, em geral, as diferenças observadas. são insuficientes para mudar o valor de alguma componente da côr, como o valor ou o croma.

Considera-se que, para um dia de luminosidade normal, o periodo mais indicado para determinações de côres, por ser menos sujeito a enganos devidos à luminosidade, é entre 8 e 16, ou, no máximo, até às 17 horas (para dias longos de boa iluminação). 


\section{COLOR IN RELATION TO MOISTURE LEVEL OF SOME SOIL SERIES}

\section{SUMMARY}

Several soil properties are used for identification and classification of soil series, of which color is one of great importance.

It depends upon a group of factors as color is particularly sensible to the influence of soil moisture.

At the Central Experiment Station in Campinas a study of color was made by employing natural and prepared samples of soil series ranging from dry soil to soil with highest moisture content, whereby the Mansell Soil Color Charts were used for color determination.

As for prepared (air-dried and sieved) samples, they may not be given representative colors as of the natural soil samples. Their variation in color is beyond that found in the field.

Series of the imperfect group up to the very poorly drained slowed the greatest moisture-level influence in the color of natural soil. Commonly these series are admitted to wider variation in color or under some circumstances these p-operties are not accounted for in identification.

The well drained soil color variations derived from moisture level between series specified limits. The field work mapping can be done in this region at any time if the critical point is the color determination.

The best moisture condition for soil color determination is that close to the natural conditions.

The moisture variation has significant effect on the VALLTE except for the aterra roxa» soil (red soil) where the CHROMA shows more sensibility. The CHROMA is the color component the least affected by moisture variation.

In the color determination of the series studied, the authors also noticed the influence of the following factors: environmental light conditions; time of determination; soil color chart conservation and exposure of samples to the air.

Since many external conditions affect the results of these determinations, they must be checked carefully for data comparison.

\section{LITERATURA CITADA}

1. MOHR, E. C. J. \& VAN BAREN, F. A. Tropical Soils, New Vork, Interscience Publishers, Inc., 1954 . p. 424-433.

2. MUNSELL, A. H. Munsell Soil Color Charts. Baltimore, Maryland, L.S.A., Munsell Color Company Inc., 1954.

3. PAIVA, J. E. (neto), NASCIMENTO, A. C., KUPPER, A (e outros). Solos da Bacia Paraná-Uruguai. São Paulo, Tip. Edanee, 1961. p. 95-104.

4. ROBINSON, G. W. Soils - Their Origin, Constitution and Classitication. London, Thomas Murby \& Co., 1951, p. 257-261.

5. VERDADE, F. C. \& HUNGRIA, L. A. Séries Monotípicas da Bacia de Taubaté. Bragantia 21:304-305. 1962.

6. - \& $\&$ Séries Monotípicas da Bacia de Taubaté. Bragantia, 21:504. 1962 .

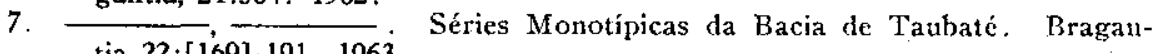
tia 22:[169]-191. 1963 . 